\title{
AXEL HONNETH E O RENASCIMENTO DA TEORIA CRÍTICA
}

\section{BENNO HERZOG E FRANCESC J. HERNÀNDEZ ${ }^{1}$}

RESUMO: A obra de Axel Honneth está entre as mais exigentes da filosofia social contemporânea. Nela, ele busca vincular a filosofia com as ciências empíricas para elaborar uma teoria crítica do reconhecimento. Este artigo oferece uma introdução crítica ao pensamento do autor alemão com todos seus problemas e questões não resolvidos. Apresenta as diferentes etapas de Honneth, desde sua crítica à Escola de Frankfurt, passando pelo desenvolvimento de sua Teoria do Reconhecimento, até a dedicação, na atualidade, a instituições sociais nas quais acredita ter encontrado um ponto de referência de institucionalização do reconhecimento. Mostra-se como Honneth tenta reatualizar a ideia da crítica e da "transcendência intramundana", ou "crítica imanente", e superar o déficit sociológico das primeiras duas gerações da Escola de Frankfurt. Não obstante, também se enuncia uma série de problemas vinculados tanto com a imanência quanto com a transcendência da crítica e com a aplicabilidade de sua teoria à investigação empírica.

PALAVRAS-CHAVE: Honneth; Teoria Crítica; Teoria do Reconhecimento; Escola de Frankfurt.

\begin{abstract}
Axel Honneth's work is among the most demanding of contemporary social philosophy. In it, he seeks to link philosophy with the empirical sciences to elaborate a critical theory of recognition. This article offers a critical introduction to the thinking of the German author with all his problems and unresolved issues. It presents the different stages of Honneth, from his critique of the Frankfurt School, through the development of his Theory of Recognition, to the dedication at present to social institutions in which he believes he has found a point of reference for the institutionalization of recognition. It is shown how Honneth attempts to re-actualize the idea of criticism and "intramundane transcendence" or "immanent criticism" and overcome the sociological deficit of the first two generations of the Frankfurt School. Nonetheless, a series of problems related both to immanence and transcendence of criticism, as to the applicability of its theory to empirical investigation, are also enunciated.
\end{abstract}

KEYWORDS: Honneth; Critical Theory, Theory of Recognition; Frankfurt School. 
Axel Honneth é, talvez, o autor menos conhecido entre os grandes da filosofia e da sociologia alemã contemporânea. Isso pode ser devido a dois fatores. Em primeiro lugar, Honneth se enquadra em uma "geração" que tomou o relevo de figuras que nos deixaram obras tão notáveis quanto difíceis de assimilar. Pensemos apenas nos livros publicados por Niklas Luhmann, que pretendem atualizar a tentativa de Talcott Parsons de construir uma grande teoria social, incorporando contribuições da teoria de sistemas ao estruturalismo, ou também na bibliografia de Jürgen Habermas e sua elaboração de uma teoria da ação comunicativa. O fato de que só agora, décadas depois das publicações fundamentais de Luhmann ou Habermas, comecemos a dispor de suficiente bibliografia secundária, demonstra, precisamente, que necessitávamos de um tempo para assimilar suas propostas que, logicamente, haveriam de eclipsar outros trabalhos. Em segundo lugar, a atenção às propostas de pensamento filosófico social depende frequentemente das urgências do mundo atual que alentaram a difusão de análises sociológicas como as de Ulrich Beck, Anthony Giddens ou Zygmunt Bauman, centradas nos riscos e perigos da pós-modernidade. Resulta paradigmático o êxito colhido por Ulrich Beck e seu livro Sociedade de risco ${ }^{2}$ (Beck, 1994 [edição original, 1986]), que não apenas estimulou outras contribuições que deram conta da sociedade pósChernobyl, mas que também contribuiu com uma série de noções (como "risco", "irresponsabilidade organizada" ou "sociedade cosmopolita") que nos ocuparam durante anos. Esses fatores explicam que as contribuições de Honneth em sociologia e filosofia, apesar de sua relevância teórica, tenham ficado eclipsadas.

Axel Honneth é hoje em dia diretor do Institut für Sozialforschung, do Instituto de Pesquisa Social da Universidade de Frankfurt, aquela instituição fundada no século passado por onde desfilaram autores tão notáveis como Max Horkheimer, Theodor W. Adorno, Herbert Marcuse, Erich Fromm, Walter Benjamin ou o mencionado Habermas. Não são só as expectativas vinculadas com tal posição institucional, no entanto, que justificam atribuir a Honneth uma posição destacada na filosofia e na sociologia contemporâneas. É sua obra (composta por uma dúzia de livros próprios e outros tantos editados por ele, assim como uma centena de artigos) e, sobretudo, a criação de uma construção teórica conhecida como Teoria do Reconhecimento, que lhe converte em figura acadêmica central para as próximas décadas.

Na última década apareceu um grande número de livros de Axel Honneth. No ano de 2009, por conta de seu aniversário de 60 anos, foi publicado um livro homenagem na 
Alemanha (Forst et al., 2010) e se aproveitou a ocasião para traduzir diversas obras ao castelhano. No começo de 2009 foi publicada sua tese de doutorado sobre A Crítica do Poder (Honneth, 2009a) e suas reflexões sobre diversos autores da Teoria Crítica em Patologias da razão (Honneth, 2009b). Também foi publicada uma antologia de textos no México (Honneth, 2010f) e uma antologia de textos-chave do autor de Frankfurt sobre A sociedade do desprezo (Honneth, 2010a). Também têm sido traduzidos os últimos livros como Patologias da liberdade (Honneth, 2016a) ou sua grande obra madura $O$ direito da liberdade (Honneth, $2014)^{3}$. Na atualidade está sendo preparada a tradução de seu ensaio sobre $A$ ideia do socialismo (em alemão: Honneth, 2016b). Com isso ficará acessível para o público leitor do espanhol praticamente a totalidade de seus livros e grande parte de seus mais destacados artigos. Em outras línguas, como inglês ou francês, e pouco a pouco também em castelhano e português, começa a se editar também uma interessante bibliografia secundária 4 .

Por esse crescente interesse pelo projeto de Honneth de reatualizar a Teoria Crítica, propomo-nos aqui a fazer uma apresentação sucinta das etapas de seu pensamento, explicando como tenta sanar o déficit sociológico que, segundo ele, padece a Teoria Crítica precedente. $\mathrm{O}$ objetivo deste artigo, portanto, é oferecer uma introdução crítica ao pensamento do autor alemão com todos seus problemas e questões não resolvidos. Por isso, esboçaremos em uma primeira parte a história da Teoria Crítica, o estabelecimento de seu projeto, as dificuldades que a mergulhou depois da II Guerra Mundial em uma espécie de estagnação e a tentativa de superá-las por parte da Teoria da Ação Comunicativa de Habermas. Na segunda parte apresentaremos a resposta de Honneth a uma situação que identifica como deficiente. Veremos seu esforço para reatualizar uma noção de crítica imanente e seu compromisso com a sociologia. Na terceira e última parte, daremos ênfase a todos os fios soltos que Honneth ou a bibliografia secundária terão que enfrentar no futuro se quiserem seguir o caminho traçado pelo autor alemão.

\section{Do surgimento da Teoria Crítica até Habermas}

Desde sua fundação, em princípios dos anos 20 do século passado, o Institut für Sozialforschung ${ }^{5}$ tem sido o centro nevrálgico da chamada Escola de Frankfurt, uma escola de filosofia e sociologia que se caracteriza por desenvolver o que formularam como Teoria 
Crítica. Os membros da Escola de Frankfurt realizaram suas contribuições a partir de uma leitura não dogmática de Karl Marx. O que nos obriga a voltar no tempo e apresentar sucintamente essa leitura.

Brincando com o título da obra mais conhecida de Honneth, bem que se poderia dizer que o problema de Marx é "o reconhecimento pela luta". No alvor da Revolução de 1848, Marx pôde abrir seu Manifesto (1848) com a afirmação "a história de todas as sociedades até agora é a história da luta de classes" porque realiza um exercício teórico duplo. Por um lado, reduz os conflitos sociais ao enfrentamento entre as classes, cujo antagonismo histórico teria se simplificado em nossa época pela luta entre dois grupos, que se define, como propunha a economia política clássica, em função dos fatores do processo produtivo: capital e trabalho. Por outro lado, outorga àquele conhecimento um caráter moral com um argumento que toma de G.W.F. Hegel: da mesma maneira que a consciência avança no saber quando enfrenta o que não é ela própria, no qual ela mesma acaba se descobrindo, o proletariado está imerso em um conflito com aquilo que, sendo seu outro, o constitui como classe: o capital. Por se ter produzido a simplificação do antagonismo, o proletariado é confrontado com a burguesia e com o próprio conflito de classes; ele é a classe universal que há de fechar o conflito social e, portanto, o meio para saber-se a si mesma como portadora de uma tarefa moral; quer dizer, deve proceder ao reconhecimento pela luta.

Ao menos desde a redação de seus Manuscritos de Paris (1844), Marx é consciente de que o que denominamos exercício teórico duplo tem também a dupla vantagem de, por um lado, evitar a tendência positivista da redução dos conflitos à luta de classes entre a burguesia e o proletariado, graças à sua localização em uma teoria geral da história e, por outro lado, de evitar o idealismo subjacente a esta teoria mediante o recurso à experiência concreta, à materialidade das lutas. E, por isso, essa explicação cumpriria os dois objetivos básicos de uma sociologia crítica: proporcionar um acesso metodológico à explicação da mudança social e estabelecer um princípio normativo que possibilite avaliá-lo moralmente. Em seus escritos posteriores, Marx ofereceu, certamente, descrições de conflitos sociais mais complexos que o que sugeriria a tese da simplificação do antagonismo, assim como reflexões metodológicas das quais se poderia deduzir um novo questionamento do idealismo subjacente à explicação anterior. Não há espaço aqui para explicar essas mudanças. O importante é destacar como, no começo do século $\mathrm{XX}$, os sociólogos reunidos em torno do Institut für Sozialforschung 
aceitaram aquela explicação geral e pretenderam atualizá-la para sua época, contribuindo, sobretudo, com uma perspectiva multidisciplinar.

As investigações do Institut buscaram, desde o princípio, vincular a filosofia com as ciências sociais empíricas recém-surgidas. Trabalharam no instituto, desde o começo, psicólogos, sociólogos, filósofos, juristas, economistas, pedagogos, especialistas em arte ou literatura contemporânea, entre outros. Com esse enfoque multidisciplinar se pretendia, ademais, colaborar no questionamento das próprias posições filosóficas e sociológicas, o que se converteu em outra das características que permitem falar de uma tradição específica: a assunção da autocrítica dentro da própria tradição.

Para entender a Teoria Crítica, com "c" maiúsculo, faz falta explicar primeiro o conceito de crítica que justifica falar de uma corrente singular. Pouco tem a ver o conceito de crítica da Escola de Frankfurt com a noção já praticamente esvaziada que se pode escutar diariamente e que significa pouco mais que a autorrepresentação do falante como progressista. Crítica, para os autores do Institut, sempre se refere à explicação que comentamos a propósito de Marx, quer dizer, uma crítica normativa imanente, uma crítica que descobre no mundo social um elemento de referência para criticar justamente este mundo atual, um ponto de Arquimedes para não apenas desvelar as contradições do existente, mas também preparar sua superação, isto é, apontar para além da sociedade dada. Por isso, Honneth fala também de "transcendência intramundana" (Honneth, 2000, p. 92) ou, em outra ocasião, de "uma forma que ao mesmo tempo é capaz de proporcionar informação sobre aquela instância précientífica na qual seu próprio ponto de vista crítico está ancorado extrateoricamente como interesse empírico ou experiência moral” (Honneth, 2010b).

Na versão da Teoria Crítica anterior à II Guerra Mundial e formulada basicamente por Horkheimer, seguindo os passos de Marx, o trabalho desempenha aquela função de transcendência intramundana. A capacidade humana de trabalhar, anterior a toda reflexão teórica, é que permite não só confrontar o mundo, mas também entender, criticar, transformar e, finalmente, superar a sociedade dada. Nesta tradição o trabalho é a ancoragem pré-teórica que possibilita uma emancipação social.

Já no contexto do exílio do Institut, que durou de 1933 até 1950 e no qual grande parte do grupo seguia seu trabalho em Nova Iorque ou na costa do Pacífico dos E.U.A., no entanto, Horkheimer e Adorno começaram a se separar dessa visão. Desde a Dialética do 
Esclarecimento (Adorno \& Horkheimer, 1998 [edição original, 1944]) até a Dialética negativa (Adorno, 1992 [ed. or., 1966]) perde-se a fé na capacidade emancipatória da classe trabalhadora. O alinhamento desta classe com o fascismo e o nazismo e a aparição da barbárie absoluta nos campos de concentração põem fim ao otimismo subjacente à explicação marxista e fazem duvidar do próprio projeto do Iluminismo. Para Horkheimer e Adorno, depois de Auschwitz, haviam-se volatilizado todos os traços de transcendência intramundana no trabalho; nenhum fato social poderia servir para a ancoragem pré-científica da crítica ${ }^{6}$. Os autores de Frankfurt pintam um círculo fechado de domínio capitalista e manipulação cultural pelos grandes sistemas megatécnicos. Esse negativismo parece guiar a Teoria Crítica por uma rua sem saída na qual a possibilidade dos sujeitos para realizar atos de emancipação fica aniquilada. Se a razão é unicamente instrumental, dificilmente poderá estabelecer algum princípio normativo; mas se pudesse fazê-lo, e aqui está o problema, faria sobre bases que não permitiriam o acesso empírico à realidade social. Naturalmente, é possível proporcionar descrições sociológicas dos conflitos sociais, mas Horkheimer e Adorno sabem que, sem traçá-las sobre o horizonte de um princípio normativo, tais descrições não podem ter nenhuma força vinculante. Na terminologia anterior: pode haver um "conhecimento das lutas" (o que habitualmente se chama "sociologia do conflito"), mas não um "reconhecimento pelas lutas", no sentido que, já vimos, cunhou Marx.

Este é o problema que tenta resolver Habermas, o membro mais destacado da "segunda geração" da Escola de Frankfurt, e que o levará a elaborar sua Teoria da Ação Comunicativa (Habermas, 1981), na qual pretende recuperar as ideias da crítica imanente e da transcendência intramundana já comentadas. Advirta-se que quando Habermas assinala o déficit sociológico no qual havia incorrido a primeira geração, não está julgando as investigações sociais que levaram a cabo, nem sequer suas tentativas de estabelecer um princípio normativo, mas precisamente a impossibilidade de voltar a articular ambos os momentos sobre a base da crítica da razão instrumental. Trata-se de recuperar, segundo Habermas, a vontade original da Escola de Frankfurt: a articulação de ambas as exigências que se enuncia com o conceito "Teoria Crítica". No começo dos anos 80 do século passado, Habermas está convencido de que sua teoria permite recuperar aquela vontade, e em definitivo reconstruir o materialismo histórico, abarcando as pretensões normativas que se encontram a priori na ação comunicativa. Os grupos sociais estão em conflito porque emergem pretensões contrapostas; entretanto, ao fazê-lo, compartilham o horizonte de um "entendimento comunicativo", ao qual pode acessar o investigador social conhecedor da 
lógica da argumentação. $\mathrm{Na}$ medida em que esse horizonte representa um princípio normativo, podem-se julgar as pretensões dos grupos sociais.

A ação comunicativa, como resposta às teorias sociais negativistas, abre novamente o acesso a uma esfera emancipatória da ação. No contexto de uma virada linguística em muitos campos das ciências sociais, Habermas se separa do paradigma marxista da produção e cria o próprio paradigma da ação comunicativa. O que para o marxismo significava o trabalho, agora o representa a linguagem. Disse Habermas que "o entendimento é imanente como telos na linguagem humana" (1981: 369). Quer dizer, pelo fato pré-científico de que, como pessoas, estamos capacitados a nos comunicarmos mediante a linguagem, segue-se, daí, uma linha de emancipação para o entendimento. Seu objetivo é, portanto, "analisar o saber pré-teórico dos falantes competentes, os quais podem, por si mesmos, distinguir intuitivamente quando tratam de exercer influência sobre os outros e quando se entendem com eles" (1981: 369).

Três pretensões de validade estão incluídas nos atos de fala, segundo Habermas: a retidão, isto é, entender-se com alguém; a veracidade, que seria dar-se a entender a si mesmo; e a verdade, que equivale a entender sobre algo. Quer dizer, os atos de fala servem para a criação de relações interpessoais (retidão), a apresentação dos sujeitos (veracidade) e a exposição de estados e eventos (verdade). Cada ato de fala pode ser afirmado ou recusado segundo cada um dos três critérios, criando desta forma uma base de entendimento normativo que serve de ponto de referência para futuras relações. De certo modo, encontrar-nos-íamos diante de um exercício teórico duplo análogo ao de Marx. Os conflitos são reduzidos às lutas em torno de pretensões de validade e se outorga a esse conhecimento um caráter moral. Com isso, não se compromete com os compromissos filosófico-históricos que carregava o marxismo, pelo que parece ficar a salvo da linha crítica da primeira geração, mas tampouco com o pessimismo, ou melhor, com a desesperança de Horkheimer e Adorno.

Mas Habermas sabe, como manifestará depois de sua disputa com Niklas Luhmann (Habermas \& Luhmann, 1971), dos poderes sistêmicos que impedem a livre comunicação que, segundo sua teoria, deve levar à emancipação. Seu diagnóstico da época, portanto, é o da colonização do mundo da vida, na qual o poder dos sistemas cresce até o ponto em que se converte em uma ameaça para os potenciais comunicativos. A solução consiste, então, em criar uma constelação na qual o discurso pode se desenvolver livremente, quer dizer, em estabelecer uma ética do discurso baseada na participação. Mas esta proposta contrasta com 
outras posições sociológicas que se centraram na inexistência de um discurso à margem do poder. Vejamos com cuidado esse problema.

Ao trocar o trabalho marxista pela linguagem, Habermas não satisfaz a todas as exigências vinculadas com a ideia de uma crítica imanente. Ainda que a linguagem seja uma categoria pré-científica e Habermas mostre a gramática normativa que aponta para o entendimento, isto é, para a emancipação, há alguns problemas principais vinculados com essa renovação da Teoria Crítica. Na crítica marxista o proletariado adquire conhecimentos específicos e sentimentos de injustiça, o que quer dizer que se tem uma experiência moral que a teoria apenas articularia. Mas, pergunta Honneth: "que fenômenos em geral assumem na teoria de Habermas o papel de testemunhar cotidianamente, antes de toda reflexão científica, a conformidade da crítica?" (Honneth, 2010b). Na teoria de Habermas, a ação comunicativa

\footnotetext{
se realiza à margem dos sujeitos implicados; seu transcurso nem está baseado em intenções individuais, nem em absoluto está dado plasticamente à consciência de um ser humano individual. O processo de emancipação, sobre o qual Habermas sustenta socialmente a perspectiva normativa de sua Teoria Crítica, não se reflete como tal nas experiências morais dos sujeitos implicados (ibid.).
}

Esta crítica da falta de experiência moral e da conscientização generalizada vincula-se, também, com uma crítica ao elitismo da teoria da ação comunicativa, já que o novo "sujeito transformador", seguindo o fio argumentativo de Habermas, são apenas aquelas pessoas capazes de expressar linguisticamente suas pretensões normativas. Isso explica o êxito relativo da teoria habermasiana nos anos oitenta, quer dizer, em uma fase de movimentos sociais pós-marxistas, feministas, ecologistas, etc., cuja arma principal era o argumento e aos quais tinha que parecer muito atrativa uma teoria que os convertesse em vanguarda do processo de emancipação social. Ademais, o apelo à ação comunicativa se conectava bem com outras teorias baseadas no diálogo ou na enunciação da própria palavra, dos quais haviam feito bandeira movimentos emancipatórios como, por exemplo, a pedagogia do oprimido de Paulo Freire. A ampla acolhida da teoria dialógica de Habermas, entretanto, não pode ocultar os problemas teóricos que havia levantado.

Em certo sentido, a Teoria da Ação Comunicativa também é, como no caso comentado de Marx ou da primeira geração da Escola de Frankfurt, uma teoria do "reconhecimento pela luta", só que os enfrentamentos se resolveriam na arena da argumentação. O que acontece, entretanto, se os sujeitos sociais se veem privados da capacidade de enunciar suas pretensões? Basta apelar à obra de Bourdieu, ou à obra de Foucault, para advertir que o duplo exercício 
teórico de Habermas, indicado mais acima, tem um calcanhar de Aquiles ao pressupor que todo grupo social pode enunciar satisfatoriamente suas reivindicações. Se não se pode supor isso, já que os discursos estão sempre atravessados pelas relações de poder, restam apenas duas possibilidades. A primeira seria postular uma substituição dos sujeitos envolvidos por outra instância que, mais além das relações de poder, poderia enunciar as reivindicações, seja esta um filósofo social ou um intelectual crítico. Nesse caso, entretanto, não apenas existe um risco de vanguardismo, já assinalado, mas incorre-se novamente em um déficit sociológico, porque os grupos sociais ficam à margem da enunciação e da suposição de princípios normativos. Voltam a ser substituídos. A segunda possibilidade é situarmo-nos mais próximos e ancorar a pretensão normativa no "vazio psicológico" que se abre no indivíduo que padece do desprezo, ainda que não seja capaz de enunciar sua pretensão ou de fazê-lo de maneira logicamente satisfatória. Se às formas de desprezo correspondem demandas de reconhecimento insatisfeitas, e estas podem se organizar em uma pauta que supõe exigências morais concretas, então a pretensão de um grupo de não padecer de desprezo, ainda que seja difusa ou pré-verbal, pode se converter em uma "gramática moral". A questão é, então, invertendo o lema da filosofia social desde Marx até Habermas, a "luta por reconhecimento" não como demanda insatisfeita, mas sim como princípio normativo. Este é o fio condutor da proposição de Honneth.

\section{A radicalização da Teoria Crítica por Honneth}

Como dissemos no princípio, a obra de Axel Honneth, discípulo de Habermas, não teve de momento o mesmo êxito internacional que a de seu mestre. Agora que sua obra começa a ser conhecida entre nós (Honneth, 2009a, 2009b, 2010a), há que se esperar que pouco a pouco ocupe o lugar que merece.

Desde os trabalhos para sua tese de doutorado, Honneth tenta elaborar uma nova teoria crítica que cumpra os critérios antes mencionados de uma crítica imanente e transcendente. Sua tese doutoral, que se chama "Foucault e a Teoria Crítica", forma os capítulos de 1-6 de seu livro Crítica do Poder: fases de reflexão de uma Teoria Crítica da sociedade, publicado em 1985 em alemão. Na tese demonstra o que denomina a "perda do social" ou "déficit sociológico" da Teoria Crítica, que já não é capaz de captar os processos coletivos de integração e orientação social, nem tampouco os conflitos cotidianos, dado que as sociedades capitalistas se reproduziriam independentemente dos atores sociais. Pergunta-se na dissertação doutoral se a teoria do discurso de Foucault seria capaz de satisfazer esses 
critérios, mas sua resposta também é negativa, já que a possibilidade de desenvolvimento e o dinamismo que Foucault introduz em seu modelo mediante a "prática discursiva" são interpretados por Honneth em termos de sistemas autopoiéticos; ainda que Foucault dê conta do dinamismo e dos conflitos sociais, realmente exclui os sujeitos da análise (como Luhmann) e, desse modo, sua arqueologia se reduz a uma teoria do poder sistêmico. Independentemente de que, na prática, Foucault tome em alguma ocasião posição pelos mais excluídos, sua teoria não é capaz de mostrar um ponto de apoio normativo a partir do qual se poderia criticar legitimamente a sociedade. Se tudo é discurso (ou melhor, fragmento discursivo), poder-se-ia perguntar como é possível, então, tomar uma posição fora dele para criticar o próprio discurso e as condições de sua produção social? Quer dizer, ainda que, desde um ponto de vista externo, a teoria do discurso seja capaz de mostrar contradições imanentes aos discursos hegemônicos, não pode fundamentar um ponto de partida normativo que esteja livre dos poderes discursivos e que aponte para além deles. Esse é o problema.

Quando Honneth está escrevendo sua tese, trabalhando com Habermas como assistente de pesquisa, orienta-se na direção de seu mestre. Entretanto, já em 1981 aponta algumas discrepâncias. Escreve em um artigo: "Minha suposição é que a teoria social de Habermas está constituída de maneira tal que tem que ignorar sistematicamente todas as formas de crítica social existentes que não sejam reconhecidas pelo espaço público políticohegemônico" (Honneth, 2010c). Essa suspeita o leva finalmente a rechaçar também a teoria habermasiana com os argumentos mencionados acima. Por isso, na publicação de sua tese, acrescenta uns capítulos a mais (os capítulos 7-9) nos quais se distancia da tentativa de Habermas de superar o déficit sociológico da geração precedente da Escola de Frankfurt.

Em 1992 Honneth oferece, finalmente, sua própria tentativa de solução para a reatualização da Teoria Crítica com o livro Luta por reconhecimento (Honneth, 1997). Essa teoria pretende ser uma teoria com orientação normativa que cubra o déficit sociológico, isto é, que seja capaz de "verificar" suas exigências normativas mediante uma esfera pré-científica que contenha orientação moral, mas que não acabe questionada pela suposição das relações do discurso com o poder. No reconhecimento, melhor dito, na aspiração por ser reconhecido como sujeito, encontra Honneth esse fundamento mais próximo do processo de argumentação ou de qualquer “telos de entendimento", e tão pré-científico como o trabalho.

Por isso, recorre a um modelo já desenvolvido pelo jovem Hegel em seus escritos iniciais, os quais redigiu nos primeiros anos do século XIX em Jena, sobre a luta por 
reconhecimento. A isso o conduziu a leitura de Habermas e a consciência de suas dificuldades (Boltanski \& Honneth, 2009). Hegel, naqueles escritos iniciais, anteriores à Fenomenologia do espírito (1807), distingue três modos de reconhecimento: o amor, ao qual aspira o indivíduo com suas necessidades concretas e que encontra sua expressão na família; o direito, reivindicado pela pessoa e que lhe garante uma autonomia formal na sociedade civil; e a solidariedade, mediante a qual o sujeito encontra reconhecida sua especificidade individual no Estado (prussiano).

Recorrendo à psicologia social de George Herbert Mead, entre outras contribuições, Honneth reconstrói a tipologia dos modos de reconhecimento do jovem Hegel, com a pretensão de que sejam controláveis em estados empiricamente estabelecidos. Por isso, não apenas faz referência ao potencial de desenvolvimento dos modos de reconhecimento, mas mostra as diferentes formas de desprezo que se vinculam com o não reconhecimento (tabela $1)$.

Tabela 1. Esquema de reconhecimento e desprezo segundo Honneth (1997: 159, ligeiramente ampliado)

\begin{tabular}{|l|l|l|l|}
\hline $\begin{array}{l}\text { Modos de } \\
\text { reconhecimento }\end{array}$ & $\begin{array}{l}\text { Dedicação } \\
\text { emocional }\end{array}$ & Atenção cognitiva & Valoração social \\
\hline $\begin{array}{l}\text { Dimensão de } \\
\text { personalidade }\end{array}$ & $\begin{array}{l}\text { Natureza e } \\
\text { necessidade do } \\
\text { afeto }\end{array}$ & $\begin{array}{l}\text { Responsabilidade } \\
\text { moral }\end{array}$ & $\begin{array}{l}\text { Qualidades e } \\
\text { capacidades }\end{array}$ \\
\hline $\begin{array}{l}\text { Formas de } \\
\text { reconhecimento }\end{array}$ & $\begin{array}{l}\text { Relações primárias } \\
\text { (amor e amizade) }\end{array}$ & $\begin{array}{l}\text { Relações de direito } \\
\text { (igualdade) }\end{array}$ & $\begin{array}{l}\text { Comunidade de } \\
\text { valor } \\
\text { (solidariedade) }\end{array}$ \\
\hline $\begin{array}{l}\text { Potencial de } \\
\text { desenvolvimento }\end{array}$ & $\begin{array}{l}\text { P. ex. Liberação de } \\
\text { pressões } \\
\text { econômicas }\end{array}$ & $\begin{array}{l}\text { Generalização, } \\
\text { materialização }\end{array}$ & $\begin{array}{l}\text { Individualização, } \\
\text { igualar }\end{array}$ \\
\hline $\begin{array}{l}\text { Autorrelação } \\
\text { prática }\end{array}$ & $\begin{array}{l}\text { Autoconfiança } \\
\text { Formas de }\end{array}$ & $\begin{array}{l}\text { Autorrespeito } \\
\text { Maltrato e violação }\end{array}$ & $\begin{array}{l}\text { Perda de direitos e } \\
\text { Autoestima }\end{array}$ \\
\hline \begin{tabular}{l} 
Indignidade e \\
\hline
\end{tabular}
\end{tabular}




\begin{tabular}{|l|l|l|l|} 
desprezo & $\begin{array}{l}\text { da integridade } \\
\text { física }\end{array}$ & exclusão & $\begin{array}{l}\text { injúria da "honra" e } \\
\text { da dignidade }\end{array}$ \\
\hline
\end{tabular}

Segundo esse esquema, ainda que as pessoas não disponham da capacidade de dar voz a suas pretensões de reconhecimento, elas têm uma intuição moral, normativa, enquanto existir uma sensação afetiva por uma de suas pretensões ser depreciada. A percepção dessas formas de desprezo pode motivar o sujeito a entrar em uma luta prática ou em um conflito. Mas não necessariamente tem que chegar a se expressar assim, porque forças contrapostas podem impedir sua articulação. Não é necessário, então, supor um telos de entendimento na linguagem, tal como propunha Habermas:

\begin{abstract}
para chegar a uma autorrealização conquistada, o ser humano se encontra destinado ao reconhecimento intersubjetivo de suas capacidades e operações. Se em algum dos escalões de seu desenvolvimento tal forma de assentimento social fica excluída, isso abre em sua personalidade um vazio psíquico, no qual penetram as relações negativas de sentimento, tais como a vergonha ou a cólera. Por isso, a experiência de desprezo sempre vem acompanhada de sensações afetivas que podem indicar ao singular o que o priva de certas formas de reconhecimento social. (Honneth, 1997: 166 , levemente corrigida a tradução).
\end{abstract}

A proposta que Honneth oferece, então, é de seguir a linha das sensações afetivas que se associam com as diferentes formas de desprezo. Sua obra versa, portanto, ao redor de termos negativos como "patologias sociais", "patologias da razão", "coisificação", "desintegração", "indeterminação", "desprezo" ou "invisibilidade”. Dessa maneira reafirma a ideia de crítica imanente e, ao mesmo tempo, transcendente; quer dizer, não apenas se trata de uma melhora das instituições estabelecidas, mas de aproveitar o "superávit normativo, uma mais valia de validade já estabelecida nas práticas e instituições dadas" (Boltanski \& Honneth, 2009: 113). Como exemplo, poder-se-ia recorrer ao estabelecimento de matrimônios homossexuais. Nesse contexto, as exigências de reconhecimento pretendem ampliar os conceitos de amor, responsabilidade e igualdade jurídica (dedicação emocional, atenção cognitiva e valoração social, nos termos da tabela anterior) também para as relações entre os mesmos sexos. A instituição familiar, baseada no cuidado mútuo, contém, por assim dizer, esse superávit normativo que, nas sociedades contemporâneas, está se estendendo mais além da típica família heterossexual ${ }^{7}$.

Aqui, entretanto, se estabelece a pergunta: que exigências de reconhecimento estão justificadas? Como diferenciá-las de formas “ideológicas” de reconhecimento? Já em 1994, 
Honneth está consciente de que nem todas as exigências e formas de reconhecimento apontam para um desenvolvimento social em termos de emancipação. Assim, em um artigo cita as formas de reconhecimento mútuo que se dão dentro de um grupo de jovens neonazistas na Alemanha, formas de camaradagem que se produzem junto a práticas de desprezo para com outros e que, para Honneth, exigem uma precisão maior da teoria do reconhecimento, que permita distinguir inequivocamente as formas "ideológicas" mediante uma orientação normativa clara (Honneth, 2010b). Em um primeiro momento, Honneth buscou essa orientação normativa em uma antropologia débil e meramente formal "que reconstrua umas poucas, ainda que elementares, condições para a vida humana" (Honneth, 2010d). Mas essa pergunta do que é o ser humano só pode levar a especulações infrutíferas ou a uma psicologização de fenômenos sociais. Dessa forma, Honneth parece cair, ele mesmo, no final do século passado, na armadilha do déficit sociológico que pretendia combater nas gerações precedentes da Escola de Frankfurt, incorrendo no risco de recorrer a conceitos a-históricos.

Por isso, sobretudo depois do debate com Nancy Fraser (Fraser \& Honneth, 2006), Honneth volta a buscar a orientação normativa que necessita para sua teoria nos potenciais não esgotados das instituições historicamente dadas. A teoria se torna sociológica, enfocando os mecanismos de integração e os conflitos sociais em suas diferentes formas de expressão. Nesse ponto, os conflitos não parecem por em perigo a convivência social; nem sequer se trata de conflitos de grupos antagônicos que se veem enfrentados tentando excluir-se mutuamente. Trata-se, melhor, de uma luta pela comunidade (veja-se Yar, 2001; 2003) ou de conflitos de inclusão em que se busca um modo em que todos possam ser membros reconhecidos de uma sociedade. Não se trata de lutas-contra, mas de lutas-a-favor-de.

Com isso, Honneth não rompe com a virada comunicativa de Habermas, mas a radicaliza, levando em conta formas de desprezo que não entram na esfera pública e que não estão apresentadas de forma positiva em atos de fala (que não chegam a ser verbalizadas e, portanto, não podem depurar-se argumentativamente), mas que estão coaguladas pelas relações de poder e que, e isso é importante, abrem "vazios" psicológicos nos indivíduos desprezados. Ao mesmo tempo, a teoria de Honneth permite abrir de novo a filosofia social às ciências empíricas, o que se poderia interpretar também como uma nova virada sociológica da filosofia social no sentido da pretensão original do Institut. As ciências sociais teriam agora a tarefa de seguir os fios dos sentimentos afetivos de desprezo e da gramática moral das 
exigências de justiça para encontrar, na sociedade existente, o superávit normativo que transcenda o modelo social dado.

\section{III. Últimos desenvolvimentos e crítica}

Quase um século depois da fundação do Institut e de seu programa multidisciplinar de Teoria Crítica, Axel Honneth segue trabalhando na tarefa de fundamentar uma crítica normativa imanente que, ao mesmo tempo, aponte mais além das instituições sociais existentes com um enfoque emancipatório. Para prevenir a nova emergência da barbárie, comprometido com o novo imperativo categórico de Adorno de que Auschwitz não se repita, Honneth tem como única arma o uso da razão e a incessante dedicação tanto aos clássicos da filosofia social, como aos debates sócio-filosóficos atuais. Em seus múltiplos artigos, Honneth volta, uma e outra vez, aos primeiros autores da Teoria Crítica e à também chamada "periferia" da Escola de Frankfurt. Em discussões com autores internacionais - como com Nancy Fraser (Fraser \& Honneth, 2006) e Luc Boltanski ${ }^{8}$ - e em debates político-sociais como a polêmica sobre o comunitarismo (Honneth, 1995), sobre as concepções da sociedade civil (Honneth, 1996) e sobre a solidariedade (veja-se Herzog e Hernàndez, 2009) -, mostra seu compromisso com os movimentos sociais que apontam para a superação do sofrimento, percebido por Honneth em múltiplos campos do social. Com isso, mostra-se disposto a escutar, ler e aprender de seus críticos, de seus companheiros e dos clássicos. Honneth se atreve a recuperar, com a revista WestEnd, o projeto de uma publicação periódica do Institut. E, uma e outra vez, retorna a Hegel como base de todo projeto de crítica imanente. O livro sobre o sofrimento de indeterminação, baseado em conferências em inglês que se ampliaram para sua posterior publicação em alemão (Honneth, 2001) e castelhano (Honneth, 2016a), inscreve-se em uma tradição de análise da obra de Hegel por parte da Escola de Frankfurt. Ao filósofo do século XIX dedicaram livros Adorno e Marcuse, sem esquecer os que escreveram outros autores influentes, como Georg Lukács ou Ernst Bloch. Uma e outra vez, Honneth destaca a importância que tem para ele voltar a Hegel, que representa a base tanto de sua teoria como da ação comunicativa de Habermas e, realmente, de toda a tradição da Teoria Crítica (p. ex. Em Boltanski \& Honneth, 2009 e em Honneth, 2010e).

Muitos de seus artigos ainda não estão acessíveis para o público falante do espanhol ou do português. Levando em conta que a Teoria do Reconhecimento não apenas engloba os conflitos clássicos de distribuição ou de reconhecimento identitário, mas vai mais além ao captar a globalidade de sensações de desprezo, o impacto que poderia ter este conceito para o 
entendimento e, portanto, também para o desenvolvimento de múltiplos conflitos sociais na América Latina é imenso, como já assinalou G. Sauerwald (2008). Ademais, os artigos traduzidos de Honneth se acham dispersos em um grande número de revistas e editoriais, o que dificulta a apresentação do seu pensamento como uma obra completa. Para falar de uma obra completa - no sentido de uma construção teórica acabada (se tal coisa pode ser dita para alguma das teorias sociais que, por definição, sempre se encontram no espaço inacabado do social) -, entretanto, a Honneth falta ainda muito caminho a percorrer, se quer demonstrar empiricamente a sensação afetiva de desprezo que, segundo ele, possuímos de forma intuitiva. É possível expressar de forma empírica essas sensações negativas? E o cientista que tentar fazê-lo não entraria, novamente, no âmbito linguístico envenenado pelos guardiões do discurso, convertendo-se, dessa forma, na própria vanguarda que Honneth critica na obra de Habermas?

Um dos problemas mais importantes dentro da teoria de Honneth é a tensão entre imanência e transcendência. As sensações afetivas de desprezo e as exigências de reconhecimento vinculadas com elas não são uma constante antropológica, mas se apresentam mediadas já em sua percepção subjetiva pelas sociedades existentes. Como uma exigência assim pode apontar para além da sociedade dada? E como se pode saber, então, a partir da Teoria Crítica, a quais das exigências deve-se levar em conta, quer dizer, quais das exigências estão justificadas e quais não (e, portanto, resultam ideológicas)?

Já faz tempo que Honneth se distanciou de sua intenção de encontrar uma constante antropológica do reconhecimento, um enfoque que o próprio critica como demasiado psicológico e muito pouco sociológico (p. ex. em Boltanski \& Honneth, 2009). Segundo sua compreensão atual, os seres humanos aprendem, durante o processo de socialização, a gramática moral à qual têm que adaptar suas exigências de reconhecimento e de justiça. Só aquelas exigências que se formulam segundo as três categorias anteriormente mencionadas, as necessidades (família), a igualdade (Estado) ou as capacidades (sociedade/trabalho), têm a possibilidade de serem escutadas. Com essa restrição, Honneth abre um amplo espaço para a universalização de princípios de reconhecimento e de justiça, mas os limita ao mesmo tempo ao espectro normativo básico já estabelecido.

Outra pergunta vinculada com a relação entre teoria e realidade empírica seria: o que acontece se se encontram respostas diferentes para o mesmo conceito normativo, ou se dois conceitos se chocam mutuamente? Assim, poder-se-ia imaginar a pretensão de 
reconhecimento em forma de um salário mais elevado por capacidades ou esforços maiores, o qual significaria um desprezo relativo para com pessoas com menor salário, e que também estariam em competição com a exigência do reconhecimento da igualdade. Em algum lugar, Honneth fala que na educação se dá essa dualidade de formas de reconhecimento. Esses problemas não podem ser respondidos apenas a partir da teoria, mas requerem uma análise social, uma análise que se possa orientar a respeito de outra categoria chave de sua obra, muitas vezes contornada: a luta, o conflito como mecanismo de desenvolvimento social.

O enfoque de Honneth se presta também à realização de múltiplos trabalhos empíricos, dos quais sempre se nutriu sua própria teoria. As perguntas desse tipo de investigação estariam vinculadas com o superávit normativo nas instituições e com as exigências de reconhecimento encerrados nas sensações de desprezo e nas reações práticas frente a eles. Aqui, a virada da teoria linguística de Habermas para o conhecimento, as instituições, práticas e afetos, alia-se com a mesma virada que se pode observar atualmente na teoria do discurso que se desenvolve na Alemanha, com uma potente orientação sociológica. A análise do discurso baseada na sociologia do conhecimento (Keller, 2005) ou a análise de dispositivos (Bührmann \& Schneider, 2008) são algumas das expressões que apelam a um modelo sociológico de análise da realidade social, que usa a noção de discurso contemplando muito mais que apenas palavras.

É aí onde entra a grande obra madura de Honneth, resultado de sua dedicação à filosofia do direito de Hegel, que começa já em Patologias da liberdade (2016). Agora, em $O$ direito da liberdade (2014), Honneth parece distanciar-se, ao menos implicitamente, da análise dos momentos de sofrimento por desprezo. Centra sua atenção mais na reconstrução crítica das esferas do reconhecimento institucionalizadas. Honneth parece haver se distanciado também - depois de sua disputa com Nancy Fraser (Fraser \& Honneth, 2006) - da ideia de uma justificação das reivindicações do reconhecimento em uma "antropologia débill", como defendia antes desse debate (veja-se, por exemplo, o texto de 1994 sobre patologias sociais: em castelhano, Honneth, 2010d). Mediante esse distanciamento, a noção de reconhecimento já não é concebida como constante a-histórica e, com isso, a-sociológica, mas imanente à sociedade (atual).

Um momento central neste (novo) desenvolvimento é a reconstrução normativa, parte central para a compreensão da crítica imanente, tal como a entende nosso autor. Honneth interpreta as instituições sociais como ordens normativas e tenta reconstruir o conteúdo 
normativo de instituições sociais como a família ou o Estado. Empreende esse caminho convencido de que a compreensão desse conteúdo normativo pode proporcionar a chave para uma maior autonomia. Por um lado, há, todavia, um potencial de desenvolvimento em cada uma dessas esferas [o "superávit normativo" dos princípios normativos (Boltanski \& Honneth, 2009)]. E, por outro lado, o conhecimento dos fundamentos normativos permite uma relação consciente com esses fundamentos, base da liberdade ou autonomia. Só ao entender as instituições sociais como algo que nos pertence, como elemento para a criação da própria personalidade autônoma, o indivíduo pode ser livre. Só desse modo o sujeito pode entrar no Reino da liberdade realizada.

Entra em jogo, aqui, o momento das patologias sociais. É justamente o desconhecimento dos fundamentos normativos das instituições sociais ou, melhor dito, da engrenagem necessária das diferentes esferas de reconhecimento, aquilo que pode levar à absolutização de uma das esferas e, com isso, a distorções patológicas da realidade social. Assim explica Honneth, por exemplo, no caso da esfera do direito, que aquelas pessoas que só pensam em uma categoria, p. ex. na categoria do direito formal, resultam incapazes de participar em todas as esferas da sociedade e, por isso, têm que sofrer de "indeterminação". Esses sofrimentos, como resultado de uma percepção errônea da sociedade, são patologias da liberdade.

Em $O$ direito da liberdade, Honneth segue com a ideia de Hegel de mostrar razões básicas das instituições sociais. Por não haver desdobrado essas razões inerentes, produzem-se em nossas sociedades patologias que minam o desenvolvimento pessoal e social, e ameaçam, inclusive, as sociedades globais. Em referência a Hegel e ao conceito de "estar-em-si-mesmo no outro" (Bei-sich-selbst-sein im Anderen), Honneth afirma que o sujeito só é livre "se encontra no marco de práticas institucionais a um outro, com o qual se vincula numa relação de reconhecimento mútuo porque pode ver nos objetivos deste uma condição da relação de seus próprios objetivos" (Honneth, 2014: 86). E igualmente com referência a Hegel, Honneth denomina "eticidade" a esta esfera de práticas sociais institucionalizadas de reconhecimento mútuo. A Honneth interessa sobretudo o potencial normativo dessas esferas, quer dizer, as promessas de reconhecimento incluídas na institucionaização da família/amizade, do capitalismo e da democracia. Não obstante, a análise normativa se refere também aos retrocessos históricos no desenvolvimento desse potencial e aos entrelaçamentos das três esferas. Seu livro, portanto, pode ser lido também como um aviso sobre as más formações 
existentes ou possíveis de nossa sociedade contemporânea ou, para dizer com palavras de Honneth, de possíveis patologias sociais.

A respeito da questão metodológica de como perceber sofrimentos ou patologias sociais, Honneth dá uma resposta indireta em sua obra. Uma e outra vez volta-se sobre produtos estéticos, sobre livros, como sobre a obra "O homem invisível" de Elison, sobre música (Honneth organiza uma conferência sobre Bob Dylan), ou sobre filmes, p. ex., o filme "Kramer vs. Kramer", que interpreta em $O$ direito da liberdade como um filme sobre patologias jurídicas. Podemos, inclusive, dizer que Honneth segue toda uma tradição de "Estética do reconhecimento" (Hernàndez \& Herzog, 2015), presente na quase totalidade dos autores da Escola de Frankfurt. A concentração em aspectos estéticos nos permite perceber o sofrimento como linguagem universal, que pode ser entendida empaticamente por outros. Dessa forma, evitam-se problemas relacionados com a distorção do espaço público pelo poder, relacionado com o linguístico.

As perguntas pela gramática moral, pela emancipação, pela possibilidade de formas de vida livres de patologias sociais e pelas possibilidades da crítica devem parecer antiquadas em um mundo sociológico no qual o positivismo dominante, o impacto imediato e as investigações vinculadas às instituições existentes ameaçam substituir as reflexões sociológicas por meros exercícios descritivos de pesquisas de opinião, quer dizer, por investigações que se limitam a pintar a situação existente, sem a ambição de melhorá-la. Se a Teoria Crítica se mantém com vida hoje em dia, se ainda prossegue em seu esforço de autocrítica e de exigência conceitual, é porque intui que seguimos vivendo em uma sociedade cuja racionalidade patológica produz múltiplos mecanismos de desprezo.

\section{NOTAS}

1 Benno Herzog e Francesc Jesús Hernàndez são professores do Departamento de Sociologia e Antropologia Social da Universitat de València. O presente artigo é uma versão ampliada, atualizada e ligeiramente corrigida de nosso artigo em espanhol, com o mesmo título, publicado na Revista da Faculdade de Direito de Caruaru / Asces Vol. 42(1). [Versão para o português de Carlos César Barros]. E-mails: benno.herzog@uv.efs e francesc.j.hernandez@uv.es.

2 (N.T.) O título da edição brasileira, lançada em 2010 pela Editora 34, é "Sociedade de risco: rumo a uma outra modernidade".

3 (N.T.) Versão brasileira “O direito da liberdade”. São Paulo: Martins Fontes, 2015.

4 (N.T.) No Brasil, além da obra citada na nota anterior, foram traduzidos os livros "Luta por reconhecimento: a gramática moral dos conflitos sociais", Editora 34, 2003 e "Sofrimento de indeterminação", Singular, 2007. Sobre Honneth podemos encontrar o livro coordenado por Rúrion Melo, "A teoria crítica de Axel Honneth: reconhecimento, liberdade e justiça", Saraiva, 2013; Luiz Gustavo da Cunha de Souza "Reconhecimento como teoria crítica?", Luminaria, 2011; Patrícia Mattos "A sociologia política do reconhecimento: as contribuições de Charles Taylor, Axel Honneth e Nancy Fraser, Annablume, 2006. 
5 Para uma visão introdutória da história do Instituto, consultar Ludwig von Friedeburg: Geschichte des Instituts für Sozialforschung. Acessível em: http://www.ifs.uni-frankfurt.de/institut/ifs_geschichte.pdf, data de acesso 29/4/2009.

6 Deve-se dizer que, em Adorno, a arte serve às vezes para manter a esperança de que é possível ir mais além do "mundo totalmente administrado".

7 Esse exemplo foi apresentado pelo próprio Honneth no colóquio em honra de seu 60o. Aniversário em 20 de julho de 2009, em Frankfurt.

8 Veja-se, por exemplo, a revista WestEnd 2/2009 e (Boltanski e Axel Honneth, 2009).

\section{REFERÊNCIAS BIBLIOGRÁFICAS}

ADORNO, T. W. (1992), Dialéctica negativa. Madrid: Taurus.

ADORNO, T. W., HORKHEIMER, M. (1998), Dialéctica de la Ilustración. Fragmentos filosóficos. Madrid: Trotta.

BECK, U. (1994), La sociedad del riesgo. Hacia una nueva modernidad. Barcelona: Paidós.

BOLTANSKI, L., HONNETH, A. (2009), «Soziologie der Kritik oder Kritische Theorie? Ein Gespräch mit Robin Celikates». EN: JAEGGI, R., Wesche, T. (eds.), Was ist Kritik? Fráncfort d.M.: Suhrkamp.

BÜHRMANN, A., SCHNEIDER, W. (2008), Vom Diskurs zum Dispositiv. Eine Einführung in die Dispositivanalyse. Bielefeld: Transkript-Verlag.

FORST, R. et al. (ed.) (2010): Sozialphilosophie und Kritik. Fráncfort d.M.: Suhrkamp.

FRASER, N., HONNETH, A. (2006), ¿Redistribución o reconocimiento? Madrid: Morata.

HABERMAS, J. (1981), Teoría de la acción comunicativa. Madrid: Taurus.

HABERMAS, J., LUHMANN, N. (1971), Theorie der Gesellschaft oder Sozialtechnologie. Was leistet die Systemforschung? Fráncfort d.M.: Suhrkamp.

HERZOG B. \& HERNÀNDEZ, F. (2009), Honneth vs. Sloterdijk - Duelo sobre el futuro del mundo. Posdata del 6 de noviembre de 2009.

HERNÀNDEZ, F. \& HERZOG, B. (2015), Estética del reconocimiento - Fragmentos de una teoría crítica de las artes. Valencia: PUV.

HONNETH, A. (1996), «Concepciones de la sociedad civil», Archipiélago: Cuadernos de crítica de la cultura, 24: 47-55.

HONNETH, A. (1997), La lucha por el reconocimiento: por una gramática moral de los conflictos sociales. Barcelona: Editorial Crítica.

HONNETH, A. (2000), Das Andere der Gerechtigkeit, Fráncfort d.M.: Suhrkamp.

HONNETH, A. (2001), Leiden an Unbestimmtheit. Eine Reaktualisierung der Hegelschen Rechtsphilosophie. Fráncfort d.M.: Reclam.

HONNETH, A. (2009a), Crítica del Poder. Fases en la reflexión de una teoría crítica de la sociedad. Madrid: Visor.

HONNETH, A. (2009b), Patologías de la razón. Historia y actualidad de la Teoría Crítica. Buenos Aires / Madrid: Katz.

HONNETH, A. (2010a), La sociedad del desprecio. Madrid: Trotta. 
HONNETH, A. (2010b), «La dinámica social del desprecio. Hacia una ubicación de una teoría crítica de la sociedad». En: HONNETH, 2010a.

HONNETH, A. (2010c), «Conciencia moral y dominio de clase». En: HONNETH, 2010a.

HONNETH, A. (2010d), «Patologías de lo social. Tradición y actualidad de la filosofía social». En: HONNETH, 2010a.

HONNETH, A. (2010e). «Estaciones hacia una Teoría Crítica de Reconocimiento. Entrevista Con Francesc Hernàndez y Benno Herzog». En: HONNETH, 2010a.

HONNETH, A. (2010f), Crítica del agravio moral. México: Fondo de Cultura.

HONNETH, A. (2014), El derecho de la libertad. Madrid: Katz/Clave Intelectual.

HONNETH, A. (2016a), Patologías de la libertad. Buenos Aires: Las cuarenta.

HONNETH, A. (2016b), Die Idee des Sozialismus. Berlín: Suhrkamp.

HONNETH, A. (ed.) (1995), Kommunitarismus. Über die moralischen Grundlagen moderner Gesellschaften. Fráncfort d.M.: Campus.

KELLER, R. (2005), Wissenssoziologische Diskursanalyse. Grundlegung eines Forschungsprogramms. Wiesbaden: Verlag für Sozialwissenschaft:

SAUERWALD, G. (2008), Reconocimiento y Liberación: Axel Honneth y el pensamiento latinoamericano. Por un diálogo entre el Sur y el Norte. Berlin: Lit Verlag, 2008.

YAR, M. (2001), «Recognition and the Politics of Human(e) Desire», Theory, Culture and Society, 18(2/3), 57-76.

YAR, M. (2003), «Honneth and the Communitarians: Towards a Recognitive Critical Theory of Community», Res Publica, 9 (3), 101-125. 